\title{
ESPEQAL LONGEMDADE
}

\section{Previdência privada}

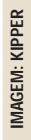

\section{A liquidação recente de planos de benefício em fundos de pensão privada chamou a atenção de autoridades governamentais e gestores privados para as fragilidades do setor, causando inseguran- ças e dúvidas no mercado. 0 momento, no entanto, não é para alarde. 0 artigo analisa a situação das entidades fechadas de previdência complementar e revela que uma série de mecanismos de proteção vem sendo tomada com o intuito de tranqüilizar seus participantes.}

por Paulo Pinheiro JORNALISTA

Apertem os cintos, o dinheiro sumiu. Do mais experiente comandante de empresa ao funcionário menos graduado, não há quem não sinta um frio na espinha quando a notícia de intervenção em uma entidade fechada de previdência privada vem à tona, como aconteceu com o Aerus, fundo de pensão dos funcionários de companhias aéreas.

Em 12 de abril deste ano, a Secretaria de Previdência Complementar (SPC), organismo responsável pela fiscalização do setor, determinou a intervenção no Aerus e a liquidação dos dois planos de benefícios patro- cinados pela Varig, deixando sem nenhum pára-quedas de segurança na velhice aproximadamente $15 \mathrm{mil}$ participantes, entre contribuintes, aposentados e pensionistas.

Em momentos de crise como este, surgem as dúvidas nos participantes dos demais fundos de pensão: 
será que meu dinheiro está seguro? A minha aposentadoria complementar está realmente garantida? Não existiria algum mecanismo para assegurar o pagamento de meu benefício mensal até o fim de minha vida?

Se o céu não está para brigadeiro, a hora também não é para pânico. Até em momentos de turbulências é preciso analisar com cuidado a situação dos fundos de pensão. Isto mesmo quando as entidades que deveriam vir a público pronunciar-se a respeito e tranqüilizar o mercado, como a Secretaria de Previdência Complementar e a Associação Brasileira das Entidades Fechadas de Previdência Complementar (Abrapp), adotam a política de avestruz, na esperança de que situações como essas caíam no esquecimento.

Por trás do caso Aerus. A intervenção em um fundo de pensão não é decidida de uma hora para outra. Há sempre uma história de malversação dos recursos e de, no mínimo, negligência por parte das autoridades do setor. Tomemos como exemplo o próprio caso do Aerus. A situação de desequilíbrio financeiro da entidade decorreu da falta de pagamentos, que não foram feitos pela patrocinadora Varig. Segundo a SPC, a companhia aérea, em grave crise financeira, devia $\mathrm{R} \$ 2,3$ bilhões ao Aerus, seu principal credor.

Conforme reportagem da Folha Online, veiculada em 12 de abril deste ano, em 2002, o Aerus modificou seus planos de benefícios para permitir que a Varig não pagasse novas contribuições para os benefícios

Atualmente, de 324 entidades fechadas de previdência complementar listadas no site da Secretaria de Previdência Complementar, quatro estão sob intervenção, sete em processo de liquidação e uma com administração especial, que é a GZMPrevi.

de aposentadoria, com exceção dos depósitos para o custeio de benefícios de risco (invalidez ou morte). Em contrapartida, a companhia assumiu o compromisso de fazer aportes de $\mathrm{R} \$ 9$ milhões mensais para honrar as dívidas em atraso. Em 2003, a SPC não permitiu mais à Varig e ao Aerus negociarem esses débitos. A Varig honrou o compromisso assumido em 2002 até metade de 2005, depois deixou de fazer os aportes. Com a aprovação do plano de recuperação da Varig aprovado em dezembro de 2005, o Aerus deveria voltar a receber novos recursos a partir de janeiro de 2006. Entretanto, em fevereiro e março, os aportes foram suspensos, o que originou a intervenção. Como se vê, até a intervenção e a liquidação dos planos de benefícios, uma série de fatos foi desenrolando-se ao longo dos anos, com a complacência das autoridades.

Evitando a insolvência. 0 mercado está livre de que fatos como estes possam voltar a ocorrer? Há quem acredite que isso seja de difícil repetição. 0 consultor Édson Duarte Jardim, da Mercer Human Consulting, empresa mundial especializada em remuneração variável, benefícios eprevidência privada, lembra que várias medidas, tanto na área financeira como jurídica, já foram adotadas no passado e até recentemente, como a Resolução n. 18, do Conselho de Gestão de Previdência Complemen$\operatorname{tar}($ CGPC), que estabeleceu novos parâmetros técnico-atuariais para a estruturação de plano de benefícios de entidades fechadas de previdência complementar, a fim de evitar a insolvência de um fundo de pensão.

A avaliação de Jardim também está abalizada nos modelos de benefícios dos atuais planos de aposentadoria complementar ofertados pelos fundos de pensão. Segundo ele, os novos planos são de contribuição definida (CD), em que o saldo final do participante determinará o valor de sua renda mensal no momento da aposentadoria.

Portanto, ao contrário dos antigos planos de benefícios definidos (BD), em que o valor da futura renda era fixado no momento de sua contratação, no CD a aposentadoria complementar vai depender do sal do que o participante conseguir acumular durante a fase de contribuição. Nesse tipo de plano, o que pode ocorrer é o benefício ficar aquém das expectativas. Ou seja, se o retorno obtido 
ESPECIAL LONGEVIDADE: PREVIDÊNCIA PRIVADA

com as aplicações financeiras não atingirem a rentabilidade pretendida, o benefício mensal do segurado ficará menor que 0 esperado.

Em contrapartida, se o rendimento financeiro ameal hado com os investimentos superarem as expectativas, o participante embolsará uma renda mensal maior que a projetada inicialmente. Em ambos os casos, com a modalidade dos planos de contribuição definida, a saúde financeira do fundo de pensão tende a ser preservada.

Para Jardim, o grande risco ainda está nos fundos em que a maioria dos planos de aposentadoria complementar é do tipo BD, ou seja, com benefícios previamente definidos e que não possam ser viabilizados. Isso porque, não importa o que aconteça durante a fase de acumulação de recursos, a entidade fechada de previdência complementar será obrigada a arcar com a renda mensal contratada pelo segurado no ato da adesão ao plano.

Atuação do governo. 0 atuário Newton Cézar Conde, da Conde Consultoria Atuarial, comenta que o problema é que a maioria dos planos hoje existentes não é de contribuição definida, mas sim mista, chamada de contribuição variável (CV). Nessa modalidade, o plano é de contribuição definida até 0 momento da concessão da aposentadoria complementar. A partir daí, com a apuração de uma renda mensal fixa, a ser paga para o resto da vida do participante, o plano passa a ser de benefício definido.

Se o segurado viver mais que a expectativa de vida estimada no ato da liberação do benefício ou se o rendimento obtido com as aplicações financeiras, durante o período de acumulação e de pagamento do benefício, não atingir a rentabilidade esperada, faltarão recursos para honrar os compromissos assumidos com os participantes.

0 governo vem se esforçando
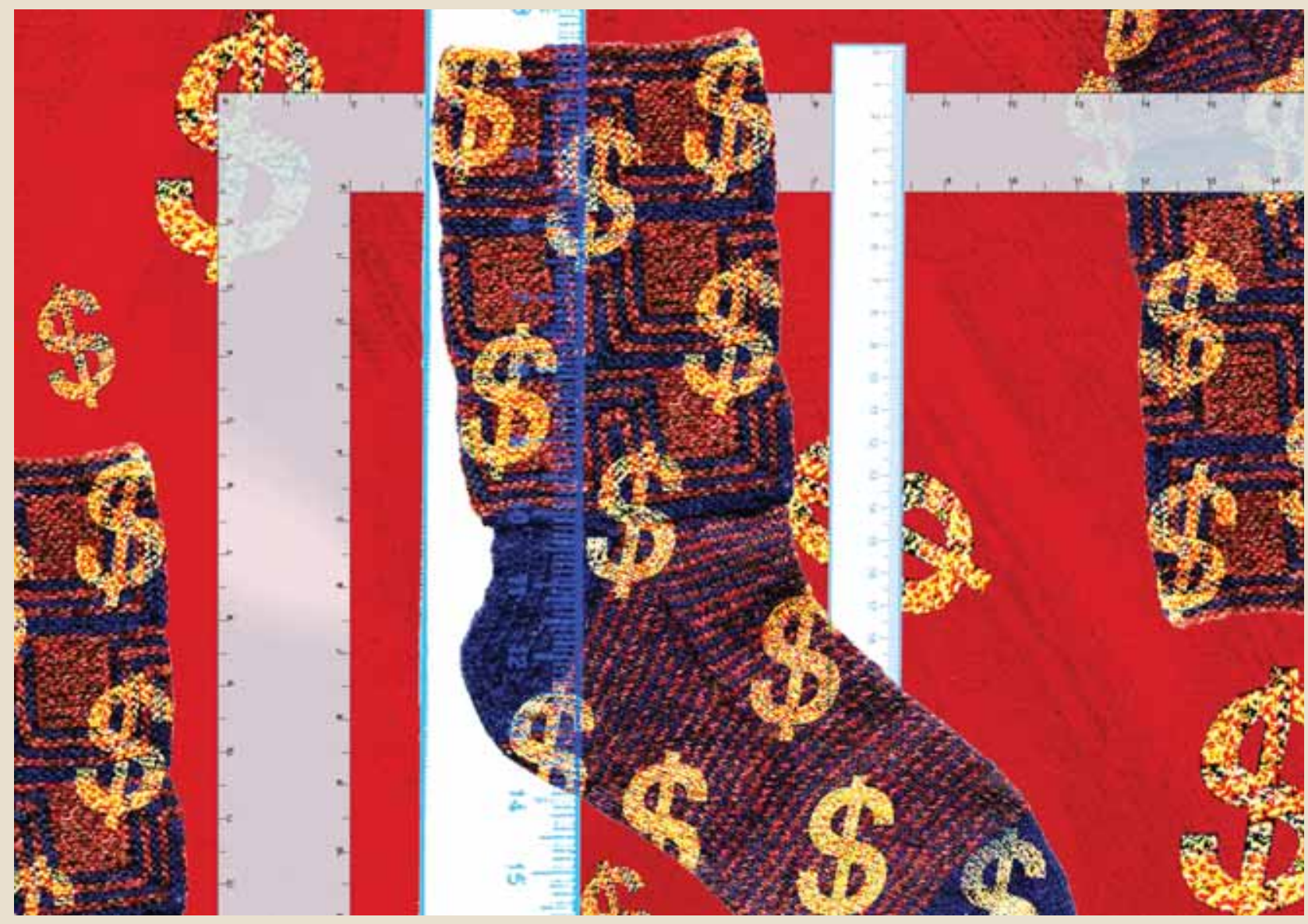
na tentativa de impedir que isso ocorra. Os padrões mínimos de estruturação de uma entidade fechada de previdência complementar estão cada vez mais severos. Em 18 de março, por exemplo, foi publicada a Resolução n. 18, do Conselho de Gestão de Previdência Complementar (CGPC), com a finalidade específica de assegurar a transparência, solvência, liquidez e equilíbrio econômico, financeiro e atuarial dos planos de benefício.

Pela resolução, por exemplo, a tábua biométrica a ser ad otada para a estimativa da mortalidade geral passa a ser a Annuity Table - 83 (AT-83), em substituição a AT-49, anteriormente definida na Resolução n. 11, do próprio CGPC, de 21 de agosto de 2002. A troca de tábua biométrica tem por objetivo utilizar uma expectativa de vida maior no momento de cálculo de um benefício, a fim de se evitarem sobressal tos no futuro. Os fundos de pensão poderão utilizar tábuas que gerem expectativas de vida superiores às da AT-83, mas não inferiores. As entidades fechadas de previdência complementar, cujos planos não estiverem adaptados à determinação do CGPC, terão até 31 de dezembro de 2008 para promover 0 ajuste devido.

Além disso, pela resolução, a SPC poderá publicar, em seu site na Internet, a relação de planos de benefícios inscritos no Cadastro $\mathrm{N}$ acional de Planos de Benefícios (CNPB), com as respectivas hipóteses biométricas e demográficas adotadas, bem como o nome do atuário responsável. Esta medida não desobriga os fundos de

0 grande risco está nos fundos em que a maioria dos planos tem seus benefícios previamente definidos. Isso porque, não importa 0 que aconteça durante a fase de acumulação de recursos, a entidade fechada de previdência complementar será obrigada a arcar com a renda mensal contratada pelo segurado no ato da adesão ao plano.

pensão da divulgação de informações aos participantes e assistidos dos planos de benefícios. Pela legislação, 0 participante deve receber uma gama de informações, por meio de comunicados e extratos, para acompanhar de perto a vida do fundo de pensão.

Os segurados também têm direito a representantes, eleitos em assembléias, nos Conselhos Deliberativo e Fiscal do fundo. Todas essas providências visam a dar maior transparência na gestão e administração do fundo de pensão.

Medi das financei ras. Do ponto de vista financei ro, al gumas medidas também foram adotadas. Até meados da década de 1990, por exemplo, os fundos de pensão podiam contar com apenas 70\% do ativo necessário para cobrir seu passivo. Por conta disso, quando os recursos para honrar os compromissos atingiam esse porcentual, os demais $30 \%$ eram negociados com a patrocinadora por meio de empréstimos ou, então, pelo não repasse de sua parcela nas contribuições dos funcionários. Esse valor devido ou retido era, muitas vezes, computado como investimento, uma vez que as patrocinadoras pagavam juros sobre o débito, dando a falsa impressão de solvência do fundo de pensão.

No fim da década passada, a SPC informou aos fundos que não mais permitiria esse tipo de negociação. Os ativos deveriam corresponder a $100 \%$ do passivo. Por causa dessa comunicação ao mercado, operações com as patrocinadoras, que envolviam altos riscos para os fundos, despencaram. Conforme o Consolidado Estatístico da Abrapp, essa rubrica caiu de R\$ 7,637 bilhões, ou 8,4\% da carteira consolidada por aplicação, em dezembro de 1998, para R\$ 70 milhões, em dezembro de 1999, ou menos de $1 \%$ da carteira. Em maio deste ano, as operações com as patrocinadoras representavam apenas R\$ 69 milhões, de um total de investimentos de $\mathrm{R} \$ 313,970$ bilhões dos fundos naquele mês.

Isso não quer dizer que as finanças dos fundos de pensão estejam saneadas. Atualmente, de 324 entidades fechadas de previdência complementar listada no site da SPC, quatro estão sob intervenção da Secretaria, sete em processo de liquidação euma com administração 
ESPECIAL LONGEVIDADE: PREVIDÊNCIA PRIVADA

Pela legislação, o participante deve receber uma gama de informações, por meio de comunicados e extratos, para acompanhar de perto a vida do fundo de pensão. Os segurados também têm direito a representantes, eleitos em assembléias, nos Conselhos Deliberativo e Fiscal do fundo.

especial, que é a GZMPrevi. Além disso, vale lembrar que a dívida da Petrobrás com o Petros, fundo dos funcionários da estatal de petróleo e o segundo maior do país, é de aproximadamente R\$ 9 bilhões, ou seja, quase quatro vezes mais o valor que a Varig devia para o Aerus.

Saídas à vista. Quais seriam, então, as saídas para garantir a efetiva concessão da aposentadoria para um participante de um fundo de pensão? Para o atuário Conde, dois mecanismos poderiam ser implementados no mercado. 0 primeiro é a instituição da figura do resseguro na previdência complementar.

As entidades fechadas de previdência privada contribuiriam para um fundo de resseguro, que honraria os compromissos assumidos com os participantes no caso de insolvência da instituição. Os recursos necessários para a criação do fundo viriam por meio da cobrança de uma taxa anual dos participantes dos fundos de pensão, como já ocorre em outros países. Embora essa medida esteja prevista na Lei Complementar $\mathrm{n}$.
109, que dispõe sobre o funcionamento das entidades fechadas de previdência complementar, ela não pôde até agora ser implementada porque a SPC tem poder de fiscalização, mas não o de regulamentação do setor.

A segunda alternativa seria a transferência, no momento da aposentadoria, do saldo do participante para uma seguradora, que é quem tem condições de assumir riscos, assegurando desta forma o pagamento de renda mensal vitalícia. Todavia a legislação vigente não permite que a transferência seja efetuada. A adoção de um desses dois mecanismos proporcionaria uma viagem mais tranqüila ao participante do fundo de pensão rumo à sua aposentadoria.

Paulo Pinheiro Jornalista

E-mail: pinhei.fnr@terra.com.br

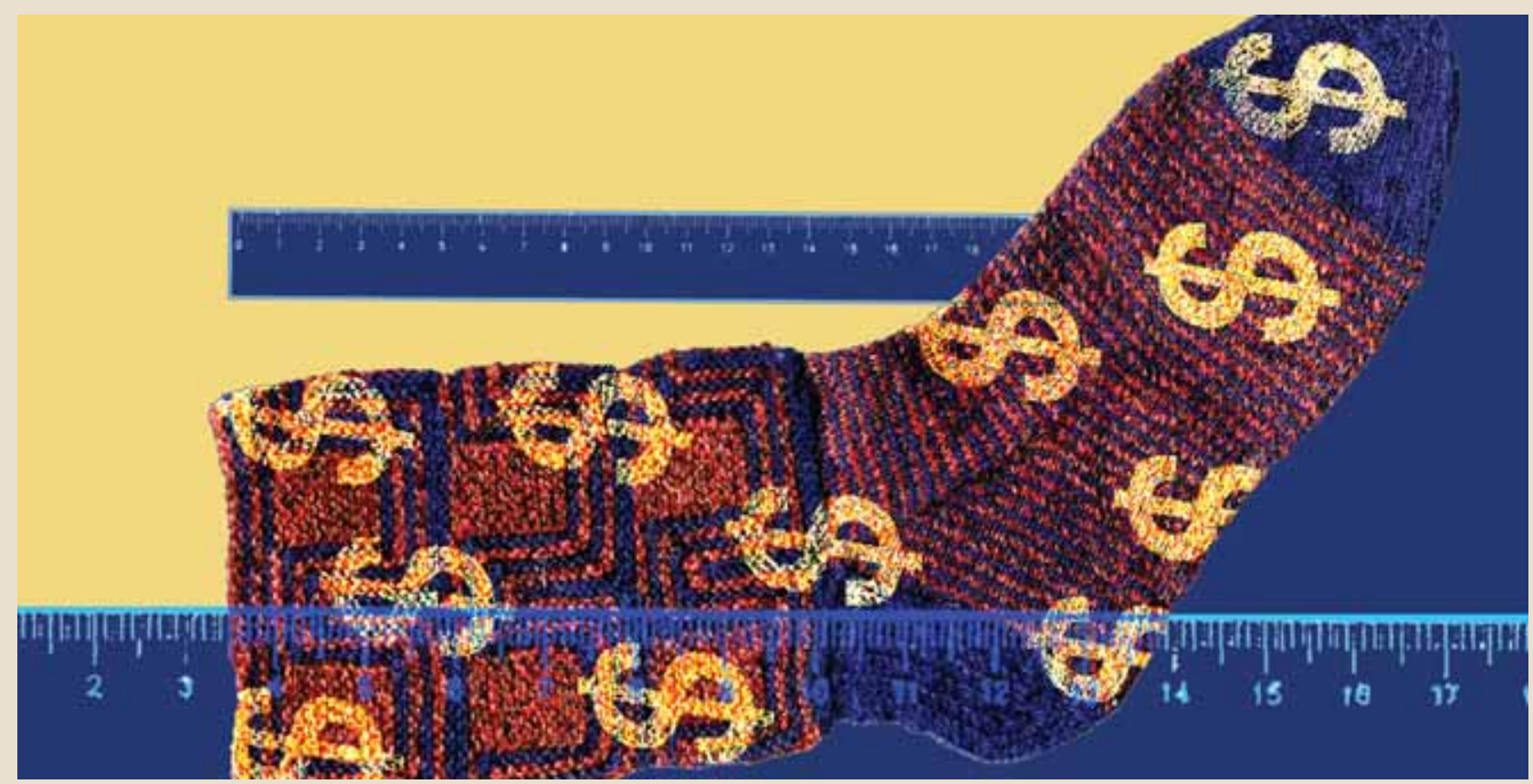

